\title{
1 TIBETAN THEATRE
}

Walking along a red-stone track dotted with monkeys, exotic birds and cawing crows, we reached the Tibetan Institute of Performing Arts in Dharamsala, in the north of India. This Institute was founded by the Dalai Lama in 1960 to promote and preserve Tibetan culture.

As soon as we arrived, we learned that we would soon be setting out for Bodhgaya, the place where Buddha was enlightened. There, the Institute was to take part, with its theatre and dances, in the Tibetan celebrations of the Kalachakra.

We made use of the few days we had before starting the trip to consult documents in the Tibetan library relating to the history of the country's theatre and dance. The material we found there was enough to keep a reader occupied for several weeks, if not months, mainly due to the fact that there is no precise information concerning this subject - all the information is spread around articles, books full of symbols, and the verbal communications of the Tibetans themselves. We worked discreetly on this material as and when we could, both before and after the trip to Bodhgaya, in the months we spent in Dharamsala.

It can be said that Tibetan theatre originated in the 8th Century AD, when the Tibetan King Chisongdegan (742-797) invited an Indian monk named Padmasambhava to preach his teachings in Tibet.

Padmasambhava arrived in Tibet in approximately 779 AD. He began preaching and came into contact with the regional festivities. Since he was a holy man, (it was he who helped to introduce Buddhism firmly in Tibet, by establishing and consecrating the first Buddhist monastery in Samye), he was asked to bless the spaces, exorcise the demons and summon up good fortune, among many other things. Everything seems to indicate that his work was that of a shaman or magician.

When he had been settled in Tibet for some time, Padmasambhava composed the Dance of the Wizard or the Dance of the Black Hat, taking 
for the composition local rhythms and elements of Tibet, many of them connected with the Bon tradition.

This shamanic dance which united rhythm and folklore was established in Tibet with the name of Garcham and it survives to this day.

Six hundred years later in 1395 a Tibetan saint, Thangton Gyalpo, took up this dance in the following way:

Myth relates that Thangton Gyalpo noted that two neighbouring villages could benefit from the exchange of their produce, but they were separated by an abyss. He therefore persuaded certain authorities to help him pay for a bridge to join the two villages. He obtained financial help and began to build the bridge. But due to certain unforeseen expenses, the money ran out before the bridge could be finished. Thangton Gyalpo knew that he could not ask his benefactors for more money, so it occurred to him to get together the most beautiful women from his group of workers, and based on the Dance of the Wizard, which by this time was famous, he organised the recital and singing of some local stories and Buddhist sayings. In this way he established a structure which spectacularly combined the telling of mythical stories, song, dance and the preaching of Buddhist sutras. The first play was called Spun/bdun (The Seven Relations). Some researchers interpret it as The Seven Brothers and others as The Seven Sisters.

So Thangton Gyalpo was able on the one hand to get together the money he needed and hence finish the bridge, and on the other hand to give rise to the birth of Tibetan opera theatre.

This Tibetan opera theatre is known as Ache Lhamo. The structure promoted by Thangton Gyalpo gained momentum as the years went by and became defined as an established cultural form of the Tibetan spirit. It was at the same time a religious and a secular structure.

Between 1617 and 1682, the fifth Dalai Lama decreed that the by now consolidated Tibetan opera should be performed separately from religious services; hence an independent art was created. It became firmly established as a secular art, respectful of religious services. This structure has prevailed to this day. 
In ancient times opera festivals were held once a year, on the Tibetan plateau; they were called Zol-ston. Nowadays in Dharamsala, there is a festival of Tibetan theatre opera held during the month of April. On this occasion, the Institute offers the public, for a period of two weeks, its entire repertoire of dances and operas.

The libretto of the opera is known as Khrad-gzun. Its dramatic structure is based traditionally on three parts: Doin, Xong and Zhaxi.

Doin is the introduction in which the narrator introduces himself and calls the fisherman, the fairies and the woodcutter, characters who appear in almost all the operas, with a greater or lesser degree of importance.

The actors are known as $l b a-m o-b a$; first they offer their prayers to the gods and ask for their blessing, requesting permission for the space which they are going to occupy in the performance. Then they discuss the plot and the characters of the opera, accompanied by songs and dances.

From there they proceed to the Xong, which forms the main body of the opera. The actors form a circle, the narrator explains the plot in a tone of litany, and at the appropriate moment certain actors separate from the circle and dance, sing and act out their roles, even performing acrobatics on occasions.

The sequence of narration and acting alternated with songs and dances is the basis of Tibetan dramatic structure. The action is accompanied and accentuated from start to finish by a drum and cymbals.

The last part is the epilogue, known as Zhaxi, which in Tibetan means blessing or good omen. These blessings are sung and danced by the whole group of actors. The performance is ended by a signal from the leading actor.

In ancient times these performances lasted from 10 to 12 hours, and a single performance occasionally lasted several days. Nowadays shortened performances can be seen, lasting only six hours.

Each opera has its own characteristic musical theme, as well as the inclusion in each one of popular dances from different regions of Tibet. These dances are known as Ache Lhamo. The monastic dances performed during the 
operas are called Cham. They are public religious dances.

The main plots of the operas are based on the narration of the lives of characters with surprising ethical behaviour. Some take as their structure previous lives of Buddha, but all include some amusing passages in which, for example, monks and nuns are satirized, to the delight of the audience, without anyone being offended.

Some sources indicate that there are nine operas documented as being classics, and others point to there only being eight. We would certify the existence of the following:

- Chogyal Norsang

- Sugkyi Nyima

- Gyasa Bhelsa

- Drowa Sangmo

- Nangsa Woebum

and the Indian dramas assimilated by Tibetan theatre opera:

- Drimeb Kundan

- Donyoh Dondruh

We were able to observe the performance of four of these operas on different occasions, obviously in their shortened version of six hours' duration since nowadays the long versions are not performed anywhere.

We can certify their real popular theatre structure. The contact and feedback with the people can be understood when one sees with one's own eyes the look of an audience open to the wonder of taking part in a moment of shared drama, a drama which helps us to discover the joy of being together, here and now, marvelling at being alive and happy. This audience breaks out in fantastic bursts of raucous laughter, eats, drinks, prays, urinates and defecates in the area around the performance, without losing its enthusiasm and attention.

We were lucky enough to see a moment of Tibetan theatre and its audience, due to being able to go to the festivities of the Kalachakra. There, 
for one month, about 250,000 Tibetans gathered together. For many of them it was the first time they had been out of Tibet since the Chinese invasion, and they had come to Bodhgaya to receive the blessing and the initiation of the Dalai Lama.

We were lucky, as this celebration only takes place in Bodhgaya once every twelve years. Otherwise, it would have been difficult to evaluate the social phenomenon which Tibetan theatre represents.

Being in the middle of this Tibetan concentration, the largest seen in exile, we were able to see that, even though the Tibetans are temporarily driven out of their external territory (bearing in mind that China invaded Tibet in 1959, obliging the Dalai Lama to set up his government in exile), they nevertheless keep their society very much alive in their internal territory; not only through keeping alive their cultural structures, such as theatre and dance, but also through the active power of their religion.

The dynamism of the country's theatrical structure has a correlation with its religious celebrations. An air of exuberant theatricality can be felt in the Tibetan atmosphere in general: the way in which they ritualise their spaces, both the actors and the monks; their sung prayers; their adornments; monastic debates; the very tasks of everyday life; everything can be seen as a constant fluid of the country's dramatic nature. We see their religious world as a ritual theatre which makes a profound reading of the universe, of the operativeness of its fluids, cycles, rhythms and vibrations: a reading of emotions and human behaviour which teaches us the path we ourselves are taking; a reading, at times surprisingly scientific and always up to date. Its religious constructions and the design of its celebrations are tools of concentration and direction of energy. But we will return to this point later on. What is important to underline now is that in Bodhgaya we discovered Tibet's dramatic nature in its very essence, both on and off the stage.

Part of the spectacle off the stage was, for instance, the striking dignity visible in the behaviour of the Khampas (Tibetan nomads, who formed the main bulk of the Tibetan guerrilla forces), with their muttering as they spat 
out their mucus, snorting it onto the ground; their phlegm; their farts and noisy defecation, mingling with the continuous hum of their chant om mani padme bum. Not to mention the visual effect of their dress: hair, coats, boots and caps which often reminded us of images of snowy landscapes in the Tibetan mountains, and which, in view of the heat in Bodhgaya, seemed bizarre. Their strong appearance of men from the mountains contrasted vividly with the presence, equally strong in its own way, of the occasional Tibetan punk.

In short, we were able to confirm the importance of the dramatising of Tibetan life, through public, political, religious, artistic and domestic acts.

Researchers such as Nicholas and George Roerich, Jacques Bacot, Giuseppe Tucci, John F. Avedon, Marcelle Lalou, among others, helped us with their writings, to acquire a greater vision of Tibetan culture.

Others, such as Samten G. Karmay, showed us areas of folklore and the Cham dance, a sacred dance with Bon influence, which in an indirect way is linked to Tibetan theatre. Cynthia Bridgman Josayma and Wang Yao directly analyse Tibetan theatre/opera. Other researchers, such as Ricardo O. Canzio, Barbara Nimri Aziz, Martin Brauem Dolma, Tashi Tsering, Nawang Tsering Shakspo and Amy Hellen, all of whom took part in the seminar run by the International Association of Tibetan Studies at the Colombia University in New York in 1982, have a great deal to say on the subject, without actually investigating theatre directly. The results of this seminar are published in Delhi, under the title of Soundings in Tibetan Civilization (Aziz and Kapstein: 1986).

The help and friendly guidance of one of these researchers, Tashi Tsering, whom we met in the Tibetan studies and archives library in Dharamsala, where he works, was invaluable, as through him we gained access to texts which were scarcely divulged and carefully guarded, and which proved important in the course of work.

The most important text about Tibetan theatre, in which we can find the guidelines for the actor, the scenery, costumes, music etc., is the Rolmoe Tenchoe, by Sakya Pandita. This text only exists in Tibetan, and its content can only be known, until now at any rate, via the verbal and written interpretations 
of it passed on by the masters of Tibetan theatre.

In addition, we were able to learn that the Rolmoe Tenchoe is inspired by the Natyasastra. This Indian text is well known as the bible of fine arts in India, and was originally written in Sanskrit.

To give the reader an idea, here is the basic table of emotions, as they appear in the Natyasastra; a table which has its Tibetan equivalents in the Rolmoe Tenchoe:

\section{Basic Emotions According To Baharata}

$\begin{array}{lllll}1 & \text { Rasa } & \text { love } & \text { Shrigaru } & \text { erotic love } \\ 2 & \text { Hasa } & \text { humour } & \text { Hasga } & \text { comedy } \\ 3 & \text { Shoka } & \text { grief } & \text { Karuna } & \text { illness } \\ 4 & \text { Krodha } & \text { anger } & \text { Raudra } & \text { fury } \\ 5 & \text { Utsala } & \text { energy } & \text { Vira } & \text { heroism } \\ 6 & \text { Bhaga } & \text { fear } & \text { Bhaganak } & \text { terror } \\ 7 & \text { Jugapu } & \text { disgust } & \text { Bibhatsu } & \text { unbearableness } \\ 8 & \text { Vismaga } & \text { astonishment } & \text { Adbhuta } & \text { amazement }\end{array}$

Before the Chinese invasion of Tibet, there were two professional theatre/ opera schools: the 'white masks' and the 'blue masks'. At the moment, the only professional group is the Tibetan Institute of Performing Arts.

In addition to this, there are also groups of country-folk who do amateur performances of the operas. The way in which these groups follow the performance guidelines is incoherent, and the dancers' movements are nervous, as are the quality of the voices and the performances themselves. Nevertheless, in spite of the precariousness of the wardrobe and the props of these groups, the quality of performance lies in their definite pledge to share with their people the phenomenon of the fantastic 'theatrical' experience.

The quality of the Institute's wardrobe and props is lavish and colourful. Its complicated designs for masks, hairstyles, hats and costumes for each of the performers, reach sophisticated extremes. 
The space in which the theatre/opera is performed is a circle approximately 15 metres in diameter, marked out in an open area so that the audience can gather round. In the middle of the circle there is always an image of Thangton Gyalpo, the holy patron of Tibetan theatre, together with a few offerings.

It is interesting to note that the offerings, both those in theatre and those in Tibetan religious ceremonies, always feature a cob. Corn, as we found out, appeared in Tibet as a symbol of worship in the year $600 \mathrm{AD}$. How did this come to be? What was its origin and how did it spread? We came across an oral tradition which tells us that for the Tibetans, corn is the primary food, a gift from the gods; this is precisely the same context in which it appeared in Central America. This could be a rich source of research.

Returning to theatrical space, the offerings and the altar to Thangton Gyalpo are the only scenery used, except for a few objects placed by the actors themselves to represent woods, rivers, mountains or houses. The circle is connected to the dressing rooms by a narrow passageway which gives the performers access. A round awning serves as an enormous parasol above the circle.

The performance begins at nine o'clock in the morning and ends at four or five in the afternoon. Just before the official opening of the opera two musicians, who accompany the entire performance, take their places outside the circle. As we have already mentioned, one plays the cymbals and the other the drum. The din of these instruments announces the beginning of the performance, and the performance itself develops according to the structure of Doin, preamble; Xong, main body of the opera; and Xhaxi, epilogue.

The Institute's performances in Bodhgaya, both of operas and of their folk dances, brought together hundreds of thousands of Tibetans. The sense of living together around the performances was another spectacle in itself. We have already spoken of the attitude of this spectacular audience who laugh and get excited with childlike innocence, while at the same time, and in the most natural way, they defecate and urinate nearby. They share not only the performances, but also the heat of the sun and the food and drink, all this amid raucous laughter and comments on the performance. Their respect for the 
dramatic action is startling, as is the fondness they exhibit towards the actors. In spite of the performance's six-hour duration, the audience's attention is always very much alive, perhaps due to the fact that some characters on stage are identical to the audience who are watching them. It is very likely that this game of mirrors stimulates their interest.

The performance ended at twilight, and at dusk at different points in the camp one could pick out the songs and dances of Tibetans moved by their theatre.

Aside from the theatre/opera repertoire, the Institute has a series of Tibetan folk dances called Ache Lhamo. This series also features some monastic dances known as Cham. This repertoire of dances was performed in Bodhgaya, in a programme which lasted two hours and which took place at nightfall in an improvised Italian-style forum, lit by western-style spotlights, before an audience gathered in a rectangular area enclosed by sheets of material, seated on the earth floor or using stones as seats. The atmosphere it created was fabulous. Amid the green of the palm trees which grew majestically across one corner of the roof of the improvised stage, the dark blue sky laden with stars, the presence of a warm-hearted, vibrant audience and the primitive stage almost cut out of the horizon, full of lively colour, it all seemed like a jack-in-the-box in motion. Add to this in the firmament some crescent moons like in a fairy story and, all around, the curious onlookers who, as they could not afford to attend the performance, were peeping in from outside the rectangle with attitudes reminiscent of Bosco or Van Gogh.

The completeness of the performance, both on and off the stage, allowed us to sense a circulating current of energy which encapsulated the whole thing. We were certain of having viewed for an instant the quality of this enormous cosmic soup in which we were all submerged. These performances, with their magical atmosphere, took place during a two-week period in Bodhgaya, as part of the Kalachakra celebrations in December 1985.

The range of musical instruments used by the Institute is wide and complicated. Suffice it to say that these instruments have been the subject 
of study for several ethnomusicologists, for instance Terry Jay Ellingson. The most striking Tibetan musical instrument, in our opinion, is the famous Dong Chen trumpet, whose size and vibratory scale are immense. We were lucky enough to witness the quality of its sound in a large number of celebrations. Good fortune brought us the privilege of sharing in an exclusive ceremony during the celebrations of the Tibetan new year, the 'Tiger of Fire' (1986) in Dharamsala. In this ceremony, presided over by the Dalai Lama, we heard music of the highest quality from these trumpets, due perhaps to the fact that on this occasion the enormous trumpets were made of silver. We shall not expand here on the matter of musical instruments, since our research leads us to concentrate on other areas. Those interested could refer to the aforementioned ethnomusicologist, whose work involves extensive coverage of the music and instruments of Tibet.

Now we would like to say something about the training of the Institute's actors. It must be emphasised that their rehearsals, and music, singing and dancing classes fit into a rather strange atmosphere. The entire Institute, actors, teachers, the administrative team - including the director - dressmakers, musicians, cooks, manager, wives and children, and 19 orphans under the age of 14 , all live in buildings around the work areas. Being a member of the Institute, therefore, is not merely a job but rather a way of life: they have breakfast and lunch, pray, rehearse and perform in the same place. Although they tend to spend their spare time in the Mcleod Ganj village, their activity essentially centres around the Institute. Given these circumstances, it is not surprising that they consider themselves to be a huge family. Rehearsal, eating and performance times are defined according to a discipline based on the needs of circumstances, that is to say that when there are festivities coming up in which the Institute is going to take part, whether it be with operas, dances or public parades, then that specific material is what is prepared. Away from such obligations, the rehearsals respond to the particular learning needs of the group: if some new members do not know certain dances, or if it is necessary to polish up the work with certain musical instruments, or if an old 
Tibetan opera teacher appears in Dharamsala for long enough to teach the group a new dance or an unperformed passage of an opera, and so on, then these factors influence the rehearsals.

Tibetan opera/theatre is a discipline designed by Tibetans for Tibetans. There is, therefore, no system - at least, not yet - whereby outsiders can structure their learning. The only way to learn it is by getting a gradual idea through the rehearsals and performances, and also by getting to know the actors and teachers better, since a large amount of information is based on oral tradition. To learn a few specific areas, the best thing to do is to attend special classes, which is what the Institute management decided we should do.

Our dance, music and singing teachers were generous with their knowledge; they helped us, without doubt, to acquire a greater understanding of the cultural phenomenon which their theatre represents, and they made a great effort during the months we spent with them to share their skills with us.

What definitely gave our learning greater depth was the discreet contact we were able to establish with a few monasteries. When you think of Tibetan monasteries, it is impossible to shake off the fictional image of huge stone buildings, in the peaks of the Himalayas, with their enormous gates covered in cryptic ironwork at which you knock and are granted mysterious access for certain periods of time and to certain spaces according to your level of understanding, and so on.

The reality, as we experienced it, is different. The monasteries we visited are in Dharamsala and its environs, in the same atmosphere as the Institute enjoys, if not in the very peaks, then certainly in the foothills of the Himalayas. The snowy peaks of Dhauladhar can be seen from there. Monasteries are dotted all around. Some are clearly defined and stand out due to their traditional rigid, white construction, with lavish ornaments on the frames of the main door, where occasionally the images of the Yidams - or doormen - turn up their moustaches with an inquisitive stare, scrutinising the visitor. The majority of these well-defined buildings are crowned with golden decorations. 
Many other monasteries can be found in the most surprising places, with no hint or sign as to their true identity, like for instance the one which is above the only video-cinema, or another one which is on the top floor of a hotel. They can be found in semi-tumbledown houses, at the bottom of ravines, or by following a small path off the beaten track. The whole village of Mcleod Ganj is littered with monastic activity, and the monasteries' locations are as surprising as the quality of their prayers.

We were admitted to the monasteries we visited strictly as visitors. Although we were eventually afforded some form of privilege, we cannot say that we discovered their secret. We know full well that the secret keeps itself, and that to discover an element of truth - about this or any other teaching - an entire life's dedication is necessary. Nevertheless, the contact with certain sources of vibration (like the strong sessions full of human warmth held by all the monks from the Gyuto Tantric College, who always displayed a Buddhist temperament and patience for our presence in their prayers), afforded us a greater understanding of the use of the voice and vibration as tools for concentration, thanks mainly to the guidance given to us by their abbot Khempo Lungrik Namgyal.

We also received guidance about meditation in motion, through the observation and practice of the dances of the 'Black Hat'. We were illuminated on the one hand by being able to watch these dances of the 'Black Hat' at the Namgyal monastery in Dharamsala, and on the other by attending the dance sessions at the Khampa-Gar monastery in Tashi Jong. In Tashi Jong there are a great number of 'Black Hat' dances which are performed from morning to night throughout the three-day duration of the celebration of the birth of Padmasambhava. There, the reverend Dorzong Rimpoche kindly invited us to build up the necessary contact to go more deeply into the study of the sacred Tibetan dance. This, combined with the practice of one of the dances of the 'Black Hat' which we performed in the Institute, helped us to understand more fully its meaning and content.

We also had the advice of the venerable Khamtul Yeshe Dorje Rimpoche, of the Zilnon Kagyeline monastery, who is also known as 'the man who 
controls the weather', on account of his facility to hold off or bring on rain. This lama, in a very friendly way, helped us with our research by showing us that both to perform a dance and to play the human bone flute, it is necessary to find the path that will allow us to do it from the heart.

The dance of the 'Black Hat' is meditation in motion. There are eight different forms which are performed in different monasteries, and a large number of variations. Each form or variation is a complete sequence. The structure is that of a warlike dance, or at least that was the case in the version we learned, which was called Lha-lhung Pay-dor, and which originated in the Tashi Lhumpo monastery. The warlike dancer frees the village from tyranny, by killing the bad king or the ego, depending on the version.

This war dance is performed according to a specific body code which has the quality of bringing the consciousness up to date, due to the deprogramming structure of its movements. Its sequences are organised such that they flow with the energy of the cosmos. They are really a mandala in motion. This dance uses for its body code the archaic designs of ritual, which are very similar to contemporary scientific diagrams. Its origins seem to be closely related to the Bon part of Tibet, a trend somewhat scorned in the Tibetan structure, but eventually recognised as another religious option within its structures.

As is widely known, the four schools of Tibetan Buddhism are:

- Nyingma

- Sakya

- Kagyu

- Gelug

Now, as an option recognised by the Dalai Lama, Bon Po can be added to this list. Since we are not Tibetologists, let us now leave the Tibetan religious schools and return to the dance of the 'Black Hat'. This dance has only three points of contact worth underlining here:

1. It is a dance, or meditation in motion, performed through a defined body alphabet; a type of mandala in motion which charges the performer with energy. 
2. The performer, allegorically, is a warrior fighting his battle, through the dance, to achieve individual and group freedom. The dance is performed in a circle.

3. This battle is essentially internal. The performer is striving to maintain the level of attention in the 'here and now', by offering energy to the essences, with energetic resonance in the external world.

These three points of contact can be applied exactly to the conchero dance of Central America. ${ }^{1}$ Its essential similarities are extraordinary. At the same time, we would point out the sacredness of the snail in both areas: Tibet and Central America.

These parallelisms - the snail, dance, corn - may be due to a type of coincidence, as Jung believes. Given the correlations, it is said that some researchers have sought a common source for Tibetan and Central American cosmology. However, so as to keep to the structure of our modest plan and not get too deeply into this, we shall limit ourselves to establishing as a point of contact between Tibetan theatrical rite and Nahuatlan theatrical rite, vibration and body movement used with the same intention, aside from the relationship of the three points of contact in the dance, mentioned above.

As we establish that vibration is a bridge of contact, musical instruments, voices and dances now take on a specific quality for us. What happens if we remove all the paraphernalia of Tibetan dance's wardrobe, and likewise remove the paraphernalia of the feathers in Nahautlan dance? Although it is clear that within its own orthodoxies each detail has its meaning, we wonder whether, if we stripped it down to the essential tool, that is to say the body alphabet (or dance movements) and its internal code (the repetition of a mantra), which contain within them meditation in motion, it would work and resist updating. Our answer, according to the research we have carried out, is affirmative, that is to say yes, it is possible to do

1 The concheros are highly organized dance groups, who practise traditional pre-Hispanic Mexican ritual dances. 
meditation in motion through these dances in a tracksuit and sports shoes, with no need for all the trimmings.

With regard to the voice and musical instruments, we focused our attention on the quality of vibration and its resonance. We found out, for instance, that the same drum, with the same type of scale, played by somebody who is thinking about crisps, obtains a different resonance from when somebody plays it keeping the beat in his mind, shall we say, at the centre of the sun. Mental polarisation is therefore more important than a certain type of virtuosity. This is specifically true of certain instruments in the field of theatre/ritual, and it should not be thought that it applies in general terms.

The same thing happens with the quality of a voice's vibration. We are more interested in a vibratory register which is well conducted mentally, than in one which is well intoned but which mentally remains on the surface. We are more interested in intention than intonation, whether it be sung in Nahautlan or in Tibetan.

It was gratifying to find out that this vibratory criterion is shared by Tibetan and Nahautlan people. This vibratory bridge which links Tibetan theatrical rite with Nahautlan, features in its possibilities the designs of participatory theatre which we perform in our workshop. In conclusion, we can point out that during our stay in Dharamsala, we were nourished by the vibratory quality of the voice, essentially with the teachers from the Gyuto Tantric College, who gave us a good lesson on what can be achieved by a register which keeps its concentration continually alive.

We took up the body code of the dance of the 'Black Hat' and found out about the structure of Tibet's theatre/opera and its folk dances, both in the Institute and in the monasteries; we also collected a few musical tools, like the human bone trumpet, the 'tingshak', or summoning bells, and some cymbals, to name but a few.

I am sure that the research and participatory theatre schemes which we work on in our workshop will reflect in certain points Tibetan influences, as well as Nahautlan and western ones, defining our work as a transcultural process. 
We were fortunate enough to receive an audience with the Dalai Lama, which took place in one of the rooms of his palace, in Dharamsala. As some of his comments are of use in our research, the interview is reproduced below ${ }^{2}$; the Taller members present in the conversation were Nicolás Núñez, Helena Guardia, and Ana Luisa Solis Gil.

TALLER: Your Holiness, first of all, we would like to thank you for your hospitality and for everything we have received from Tibetan culture and, of course, to thank you for offering us this audience. We would like to know, how do you think Mexicans interested in Tibet can best help the country?

DALAI LAMA: Well, the best thing you can do to help Tibet is spread the truth about the current situation, in political, cultural and anthropological terms. You can help us by writing articles which talk of Tibet in the contemporary world: articles about painting, philosophy, religion, dance or theatre. The important thing is that you help us to establish Tibet's presence, so that both the culture of the Tibetan world and its present condition become more widespread...

TALLER: What is this?

DALAI LAMA: A Tibetan trumpet made from bone, from our hands.

TALLER: What is it for?

(The DALAI LAMA picks it up and plays with it)

TALLER: (making a joke) If you don't know...

\section{(The DALAI LAMA smiles)}

DALAI LAMA: This is to work the Tantra. It is a very powerful tool and a constant reminder of our temporary nature. It can be used in this sense or to... (he waves it about amusingly like a club. We all laugh). How do you intend to use it?

2 The conversation, and the quotation which concludes this chapter, were recorded verbatim by Núnez in Dharamsala in 1986 and reproduced from his notes, with the permission of the Dalai Lama. 
TALLER: In our work in the theatre we use vibration to induce states of deep consciousness. We use the conch and we're thinking of using this trumpet, if you will allow us to.

DALAI LAMA: (He smiles and breathes in silence, looking at the trumpet). Yes, use it, why not, building bridges hurts nobody. Your work is a bridge between the cultural and the mystic, is that right? Use it. Do you have masks in indigenous theatre in Mexico?

TALLER: Yes, indeed.

DALAI LAMA: Are any of them made of shells?

TALLER: Yes, indeed. Incidentally, the similarities which we have detected between Tibetan and Central American designs are fantastic.

DALAI LAMA: Well, Asians, Eskimos and the Red Indians of North America do have a lot in common.

TALLER: We think the Central and South American Indians are related, as well as the North American ones.

DALAI LAMA: It's quite likely, as we all belong to the same family. In that sense there is a lot still to be confirmed. Research has not really begun yet. It's virgin territory.

TALLER: Do you think it is due to a cultural synchronism, or to the fact that Atlantis really existed as a common origin?

DALAI LAMA: I couldn't explain it exactly; a lot could be said on the matter. The reality is that we need serious research to be done into this point. It could give us a lot of surprises.

TALLER: For instance, corn is the pillar of Mexican culture, and even so, it appears in all the Tibetan ceremonies and offerings.

DALAI LAMA: Corn in Tibet is known as the original food. It is said that it was a gift, at the beginning of time; that it appeared without being sown, so 
that man could be nourished. Later, man began to grow it and the different types of corn were developed. However, in Tibet it has not been grown for general consumption. It is considered symbolic.

TALLER: It seems that recent research has discovered that corn is a food which does not attract radioactivity.

DALAI LAMA: Oh, I didn't know that, that's something new to me. So, if there is a disaster we'll be able to survive on corn... how marvellous! But there is no corn in Tibet..., all the Tibetans would have to go to Mexico. (He lets out a hearty laugh, and sets us all off). I really don't know very much about Mexico. What I do know about are those enormous hats.

TALLER: Mexican cowboy hats.

DALAI LAMA: Yes, yes, Mexican cowboy hats... Mexico is a Third World country, a country in the process of development, isn't it?

TALLER: Yes.

DALAI LAMA: I think that small or developing countries should bear in mind one very important thing, which is the realisation that it is as important to work hard to achieve their economic development, as it is to work for their spiritual development; the two must go together, with neither the spiritual nor the material aspect being neglected. If they do not work like this, the whole thing turns into a disaster. A while ago, the ex-President of Costa Rica came to see me, a very intelligent man. I was amazed to hear that Costa Rica scarcely has an army, and that they therefore have to defend themselves with other arms, the sort I agree with wholeheartedly: human rights, people's free right to choose, non-intervention, humanism. To defend ourselves with these arms we must be spiritually very strong. That is how small countries or those with hardly any army, or developing countries like Mexico can defend themselves. We must be spiritually strong.

TALLER: Those are the exact principles which govern Mexico's foreign policy and which, in our opinion, date back to pre-Hispanic wisdom. 
DALAI LAMA: Another coincidence, don't you think?

TALLER: Your Holiness, you set out these principles in your text, $A$ Human Approach to World Peace [1984], and show the urgency of this type of understanding among peoples. It is an important document which could sensitise processes. We want to ask you if you will allow us to translate it into Spanish so that it can reach the leaders of Central and South America; we are sure that some of them will be able to help, just as we are confident it will be of some use to Ronald Reagan, who received it via a friend of yours.

DALAI LAMA: Yes, of course, please do translate it. Why not? Part of the Dharma's work is to help to establish currents of positive energy. How long has the Mexican Society of Friends of Tibet been going?

TALLER: Fifteen or twenty years. The only person who knows exactly is its secretary, Antonio Velasco Piña.

DALAI LAMA: Oh, I see. I remember a Mexican colonel from many years ago, called Osorio. Do you know him?

TALLER: No.

DALAI LAMA: But you've heard of him...?

TALLER: A little.

DALAI LAMA: Well, anyway, what have you learned from the time you've spent among the Tibetan people?

TALLER: We have focused on the monastic dance, Cham. We have been to a few monasteries and the Institute. We have also studied the human voice, at the Gyuto Tantric College.

DALAI LAMA: Oh, the Cham dances and the tantric registers of Gyuto. Very good. How long have you been studying that?

TALLER: For seven months now.

DALAI LAMA: And how much longer will you be here? 
TALLER: Another month and a half or two months.

DALAI LAMA: When was the first time you came into contact with Buddhist teaching in the flesh?

TALLER: During the Kalachakra celebration, in Bodhgaya last December.

DALAI LAMA: What a good thing that you were in Bodhgaya. It was a great concentration, not only of Tibetans, but also of Dharma.

TALLER: It was fabulous to see 250,000 Tibetans from such different regions. We think it was the largest Tibetan concentration in exile, is that right?

DALAI LAMA: (Nods) The important thing is to keep the spiritual work going; that is something we must never forget, regardless of the external circumstances in which we may have to live.

TALLER: In that sense, you are a living example of Buddhist teaching (bearing in mind his attitude to the Chinese invasion).

DALAI LAMA: (Smiles politely) Is there anything else?

TALLER: If you want to send a message to the Mexican people, we will try to make sure it reaches them.

DALAI LAMA: A message? What message can I send to the Mexicans? They are human beings too, aren't they? Therefore what is good for any other human being is good for them: I would tell them not to forget that working towards peace of mind is the discipline of internal education, together with courtesy, love and compassion; they should be fully aware of that; that only through spiritual growth balanced with technological growth can the possibility emerge of living without anguish; that it is very important for them not to neglect either of these two aspects, the spiritual and the material. Anything else? 
We then exchanged with the Dalai Lama a series of personal comments, and finally left his palace convinced of his admirable coherence of action and thought. This 'simple' coherence gives him a superior place in the world. The only policy of the Dalai Lama, the god/king of Tibet, is one of living together in peace, one of good faith, where we can all seek our own happiness, for as he himself says: 'We must understand that when my enemy does something wrong against me, he does not do it to hurt me; he is simply seeking his happiness. We are all seeking happiness and we must help each other to achieve it, without hurting each other'. 